\title{
The Inadequate Treatments for Patients before and after Osteoporotic Hip Fracture
}

\section{Wong TH* \\ Department of Orthopedics, National Taiwan University, Taiwan}

*Corresponding author: Tze Hong Wong, Department of Orthopedics, National Taiwan University Hospital Hsin-Chu Branch, Hsin Chu, Taiwan, ROC Taiwan, Tel: +886-972654018; Email: tzehongwong@gmail.com

\section{Opinion \\ Volume 3 Issue 3}

Received Date: May 07, 2019

Published Date: May 14, 2019

DOI: $10.23880 /$ jobd- 16000183
Hip fracture will count for a significant problem in the aging group in the near future. Although the fracture is always being considered unexpected, either the fracture itself or the complication of the fracture treatments, patients and medical personnel should aware of the so call unexpected fractures and complications are really preventable and predictable with careful alertness.

We review four groups of our patients in the follow conditions from 2016 to 2018.

1. Osteoporotic hip fracture with age more than 70 .
2. Subsequent hip fracture of group 1

3. Fixation implant failure of group 1

4. Periprosthetic fracture after hip fracture of group 1

\section{Group 1}

There were 440 hip fractures, upon the fracture, only $15 \%$ of the patient had performed BMD study within 2 years, and $1 / 4$ of them received osteoporotic treatment. For those who did not have recent BMD data, we arranged the study and reflected more than $89 \%$ were osteoporosis (T-score <-2.5) (Figures 1A \& 1B).
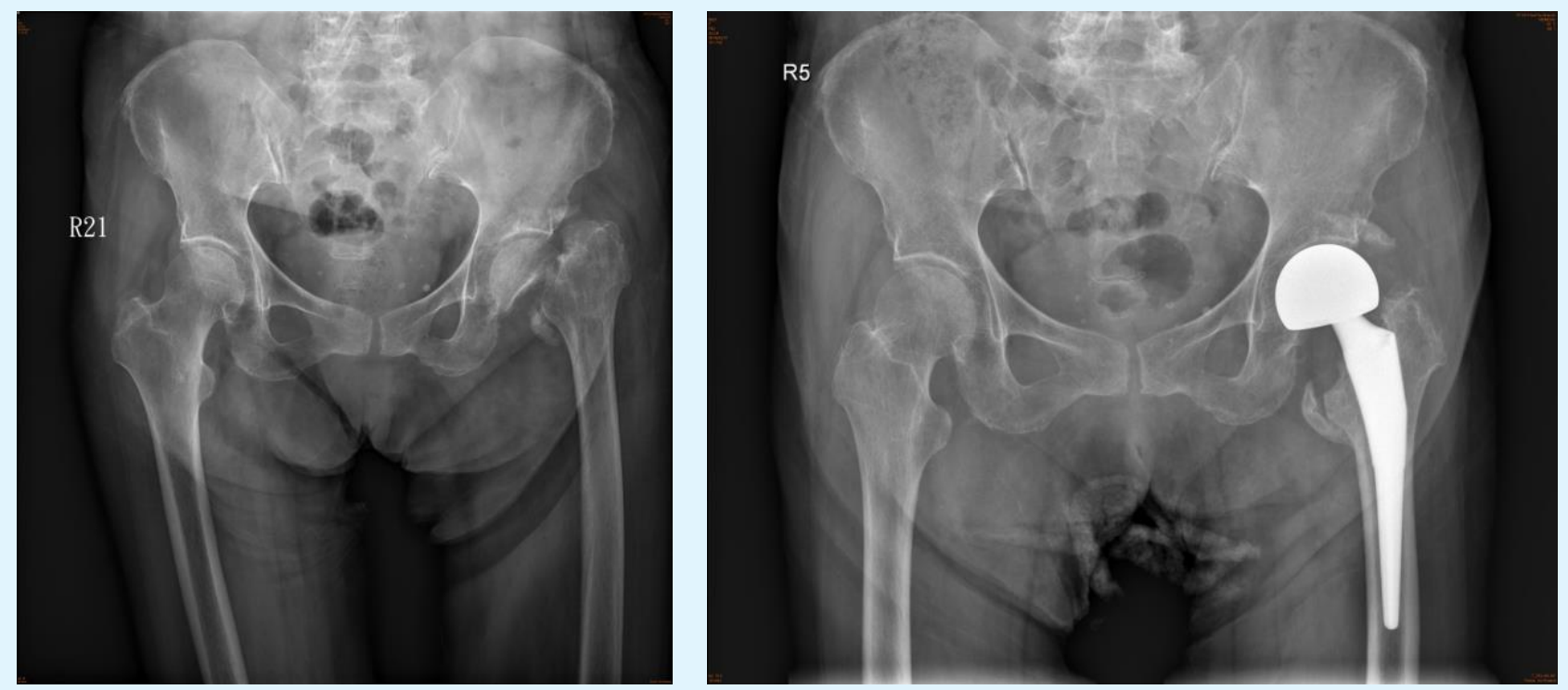

Figure 1A: 83y/o F. 


\section{Journal of Orthopedics \& Bone Disorders}

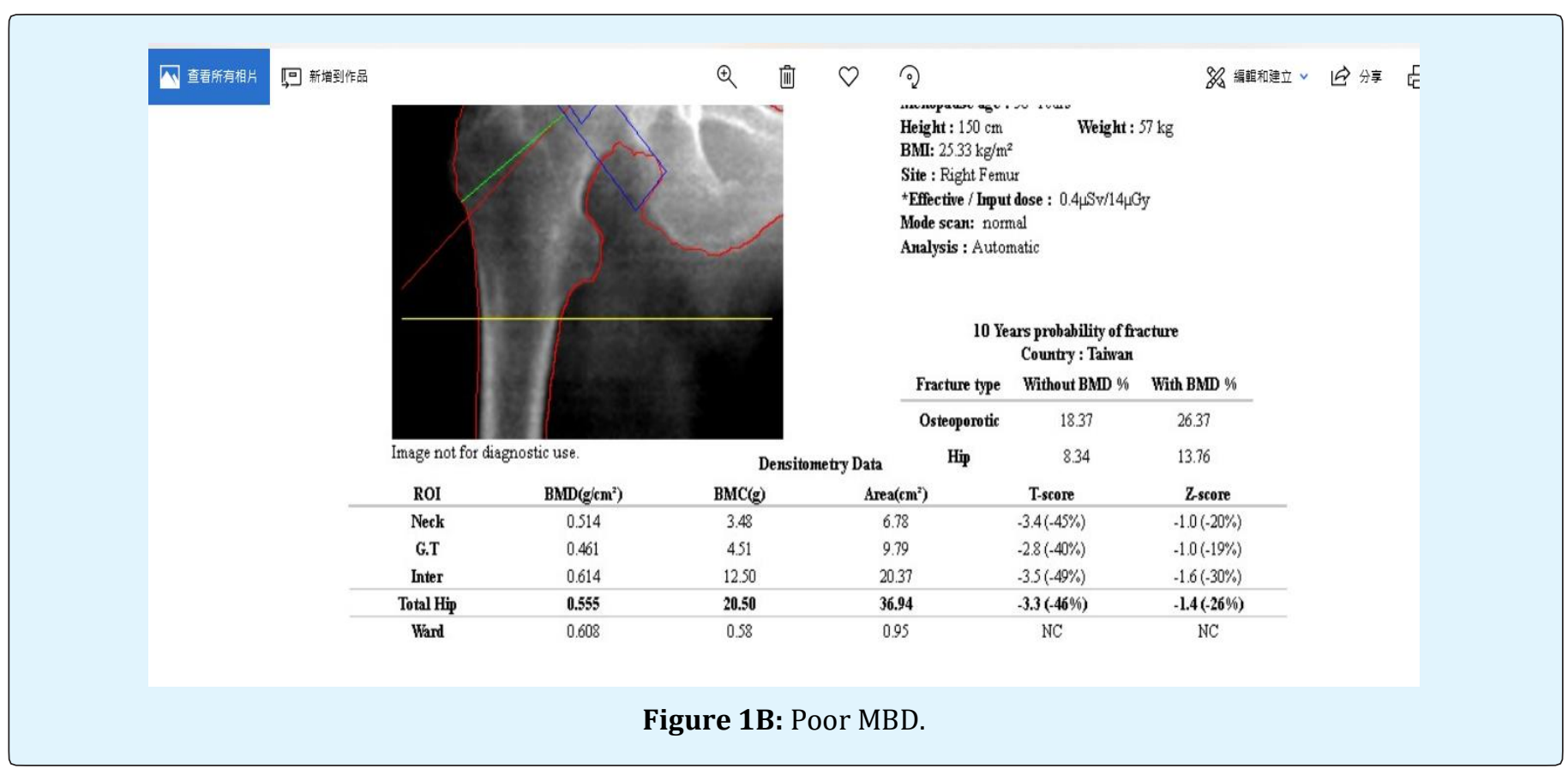

\section{Group 2}

$7.5 \%$ subsequent fracture occurred in above 440 fractures in the period of 5weeks to 26 months. The immediate BMD after fracture showed $92 \%$ as vase majority of the patients stayed at T-score -2.5 or less. While less than $10 \%$ of these patient received appropriate osteoporotic medication before the subsequent fracture for fracture prevention (Figures 2A \& 2B).

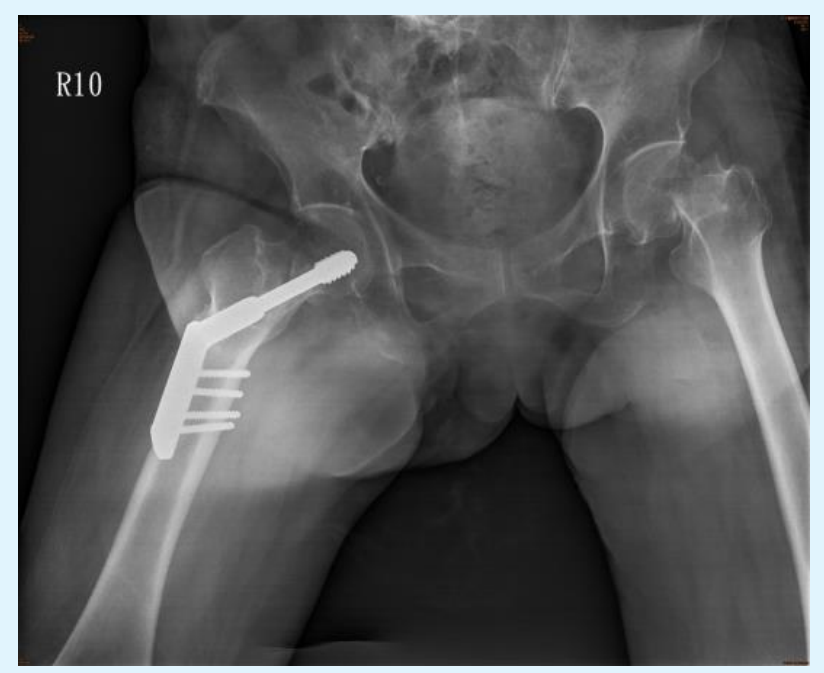

Lt subsequent fracture 26 mons s/p

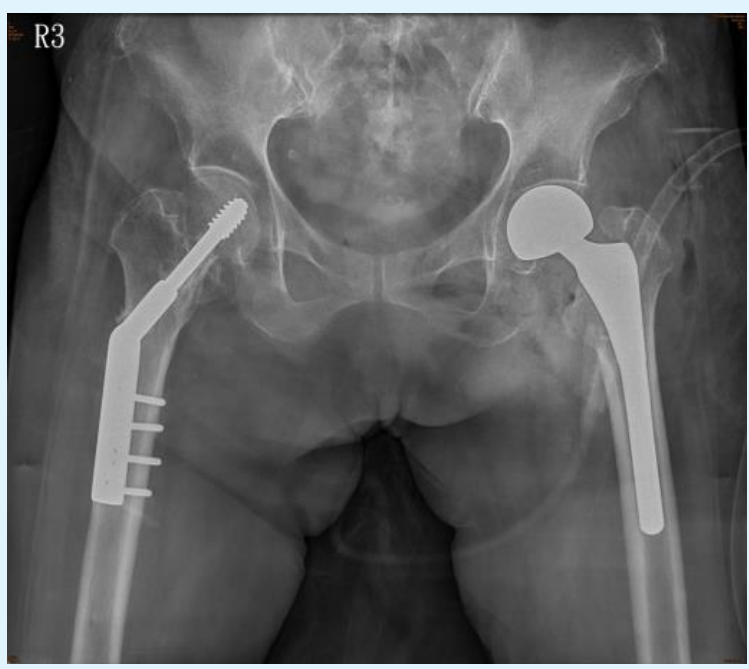

Management with bipolar

Figure 2A: 95 y/o F. 


\section{Journal of Orthopedics \& Bone Disorders}

\begin{tabular}{|c|c|c|c|}
\hline \multicolumn{4}{|c|}{$\begin{array}{c}10 \text { Years probability of fra } \\
\text { Country : Tariwan }\end{array}$} \\
\hline & & ture type & Without BMD $\%$ \\
\hline & & eoporotic & $\mathrm{NC}$ \\
\hline \multicolumn{2}{|c|}{ Densitometry Data } & Hì & $\mathrm{NC}$ \\
\hline BMC(g) & \multicolumn{2}{|l|}{ Area $\left(\mathrm{cm}^{2}\right)$} & T-score \\
\hline 8.87 & \multicolumn{2}{|l|}{13.91} & $-3.9(-40 \%)$ \\
\hline 11.09 & \multicolumn{2}{|l|}{15.96} & $-3.4(-35 \%)$ \\
\hline 12.46 & \multicolumn{2}{|l|}{15.44} & $-2.3(-24 \%)$ \\
\hline 32.42 & \multicolumn{2}{|l|}{45.32} & $-3.2(-33 \%)$ \\
\hline 8.88 & \multicolumn{2}{|l|}{11.23} & $-1.8(-20 \%)$ \\
\hline
\end{tabular}

Figure 2B: Poor BMD at subsequent fracture.

\section{Group 3}

For fixation implant failure, we noticed that poor bone quality will reduce the anchorage power for metallic implants and induce rapid implant failure such as loosening, loss of reduction Z-effect etc. Although the failure rate was $6.8 \%$ among those 440 patients, almost all of them need revision surgery. Again their BMD were unreasonably low at revision and not under any monitoring after the fracture. $(<15 \%$ treated with medication and BMD follow up) (Figures 3A \& 3B).
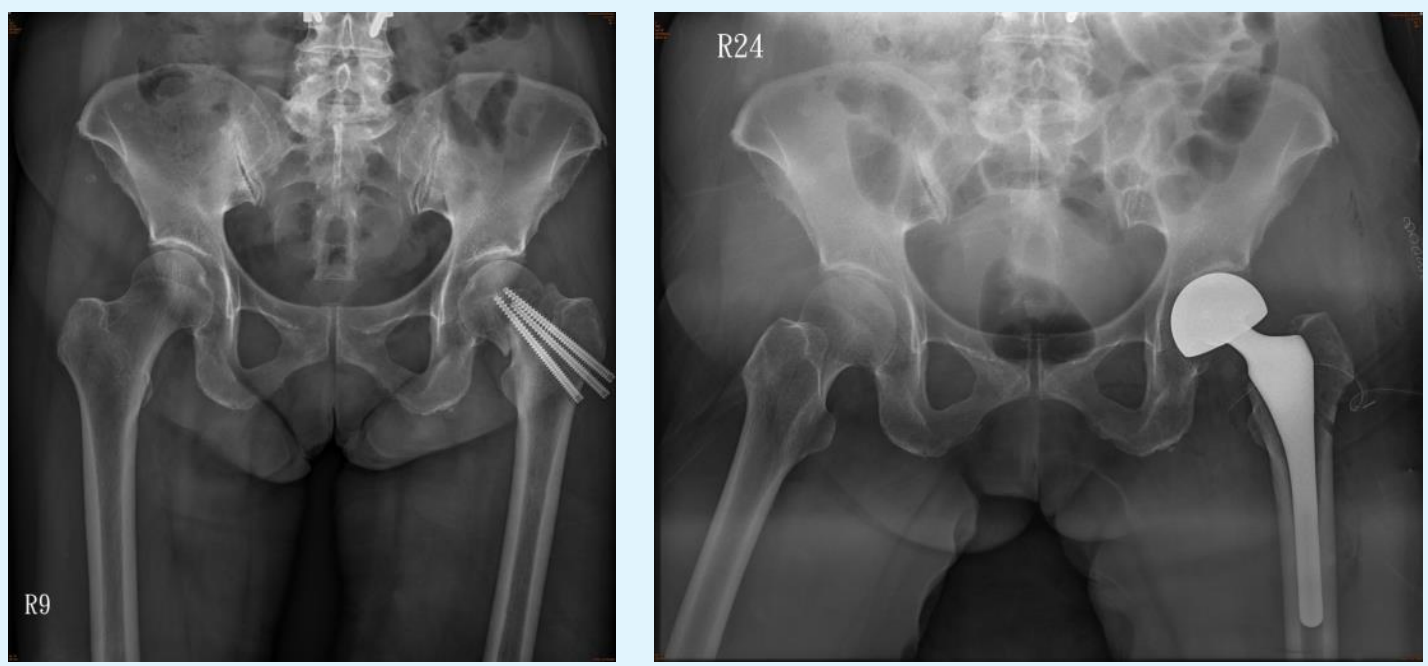

Figure 3A: 68 y/o F post op 3 weeks Revision with Bipolar prosthesis. 


\section{Journal of Orthopedics \& Bone Disorders}

\begin{tabular}{|c|c|c|c|}
\hline & \multicolumn{3}{|c|}{$\begin{array}{c}10 \text { Years probability of fracture } \\
\text { Country : Taiwan }\end{array}$} \\
\hline & Fracture type & Without BMD \% & With BMD \% \\
\hline & Osteoporotic & 8.78 & $\mathrm{NC}$ \\
\hline metry Data & Hi & 2.32 & $\mathrm{NC}$ \\
\hline \multicolumn{2}{|c|}{ Area $\left(\mathrm{cm}^{2}\right)$} & T-score & Z-score \\
\hline \multicolumn{2}{|c|}{17.41} & $-5.3(-55 \%)$ & $-3.5(-45 \%)$ \\
\hline \multicolumn{2}{|c|}{13.62} & $-3.8(-40 \%)$ & $-2.1(-26 \%)$ \\
\hline \multicolumn{2}{|c|}{31.02} & $-4.6(-48 \%)$ & $-2.9(-37 \%)$ \\
\hline \multicolumn{2}{|c|}{12.43} & $-0.2(-2 \%)$ & $1.5(21 \%)$ \\
\hline \multicolumn{2}{|c|}{12.19} & $\mathrm{NC}$ & $\mathrm{NC}$ \\
\hline
\end{tabular}

Figure 3B: Poor BMD before revision.

\section{Group 4}

$5.8 \%$ of periprosthetic fracture had drawn the attention for revisions and most of them were in Bipolar prosthesis while similar unaware status of osteoporotic treatment and study was noticed.

In these groups of patient, the so called unexpected episodes of fracture and complication were actually preventable, the inadequate awareness of poor bone quality warrant the episodes due to either uncommon BMD study or uncommon osteoporotic medication, or both (Figures 4A \& 4B).

To improve the control of these preventable issues, we highly recommended the following.
1. Routine monitoring of BMD after 65

2. To treat those who meet the criteria of osteoporotic treatment with education and medications

3. Once hip fracture suffered, continuous BMD monitoring and osteoporotic medication is mandatory

4. Appropriate implants for fixation to prevent implant failure

5. Bone quality evaluation should be done proceeding the scheduled total joint replacement surgery

6. Once a fair or poor bone quality is found, total joint replacement should be performed after appropriate management with osteoporotic medication, exercise training etc. to prevent periprosthetic fracture

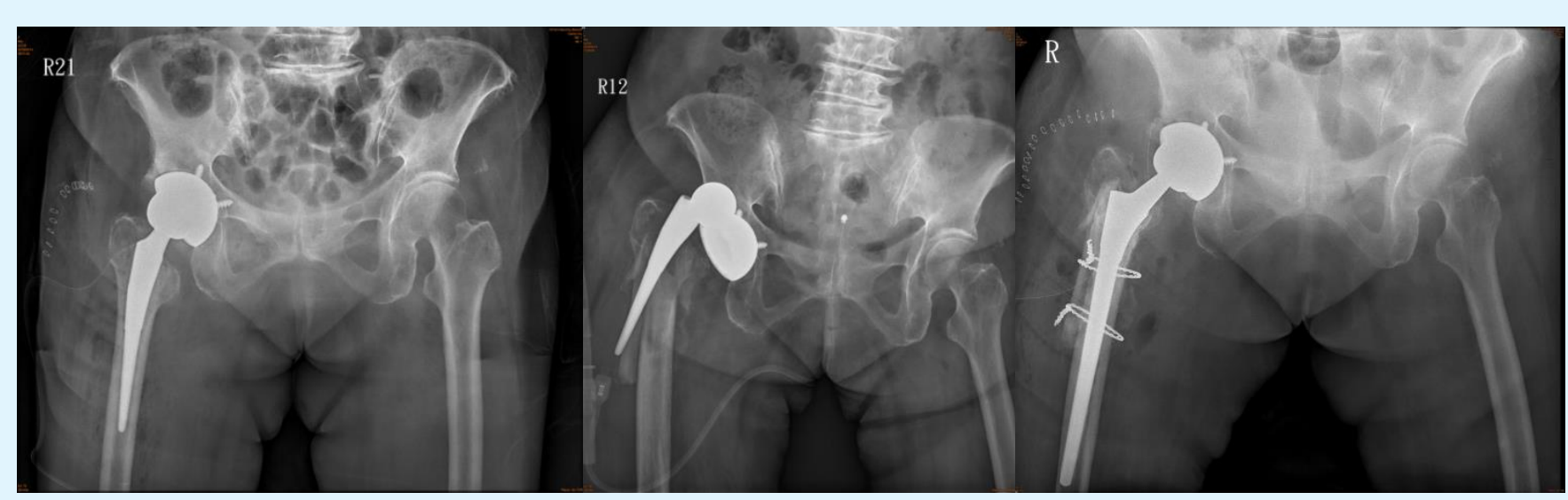

Figure 4A: 73y/o F Post op 2 weeks. 


\section{Journal of Orthopedics \& Bone Disorders}

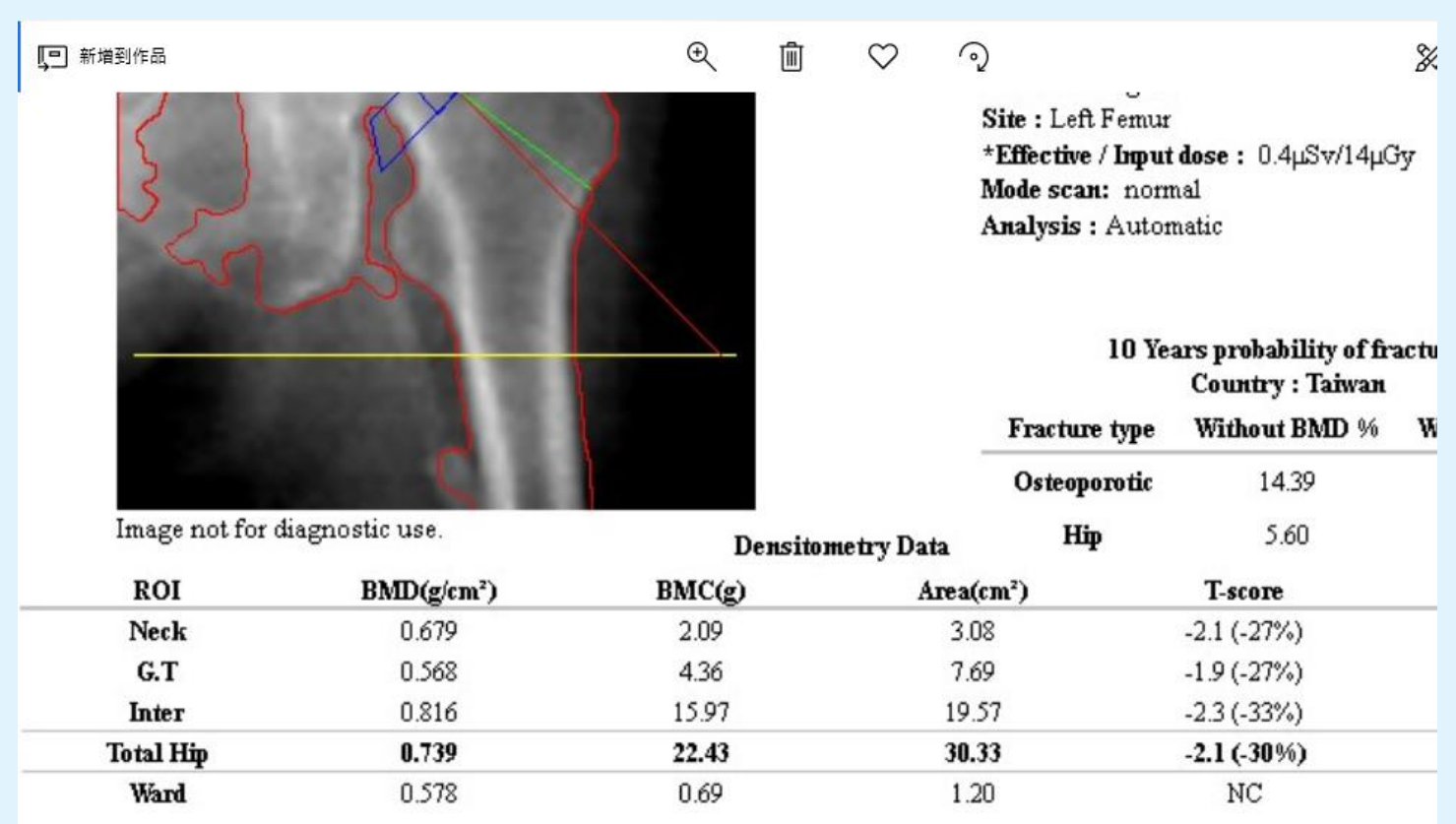

Figure 4B: Revision with long stem THA. 